SIEGEL, Frederico Adrade; NETO, Francisco José Rodrigues de Oliveira; SOARES, Josemar Sidinei. A guarda, a guarda compartilhada e o poder familiar: implicações práticas. Revista Eletrônica Direito e Política, Programa de Pós-Graduação Stricto Sensu em Ciência Jurídica da UNIVALI, Itajaí, v.11, n.3, 30 quadrimestre de 2016. Disponível em: www.univali.br/direitoepolitica - ISSN 19807791

\title{
A GUARDA, A GUARDA COMPARTILHADA E O PODER FAMILIAR: implicações práticas
}

THE CUSTODY, THE SHARED CUSTODY AND THE PARENTAL AUTHORITY: pratical implications

Frederico Andrade Siegel ${ }^{1}$

Francisco José Rodrigues de Oliveira Neto

Josemar Sidinei Soares ${ }^{3}$

SUMÁRIO: Introdução; 1 . A definição de família e a terminologia para identificar seus membros; 2. Antecedente histórico do poder familiar; 3. A definição de poder familiar; 4. A definição de guarda; 5. A guarda compartilhada e seus aspectos práticos e jurídicos; Considerações finais; Referências bibliográficas.

\section{RESUMO}

A categoria "guarda compartilhada", prevista na legislação brasileira, tem suscitado dúvida e confusão entre pais ou responsáveis pela guarda de menores, que não compreendem as exatas atribuições inerentes ao poder familiar, e acreditam que o compartilhamento diz respeito apenas ao tempo em que o menor irá permanecer na companhia de cada um. É por essa razão que se faz necessária avaliar a resposta normativa e a definição das categorias jurídicas envolvendo a criação e educação dos filhos, a partir da ruptura familiar. E para isso, utilizou-se o método indutivo.

Palavras-chave: Família. Poder familiar. Guarda. Guarda compartilhada.

${ }^{1}$ Juiz da $2^{\text {a }}$ Vara Cível da Comarca Videira/SC. Doutorando em Ciência Jurídica pela Universidade do Vale do Itajaí/SC. Mestre em Direito da União Europeia pela Universidade do Minho (Uminho) e em Ciência Jurídica pela Universidade do Vale do Itajaí (Univali). Especialista em Processo Civil pela faculdade de Direito de Joinville. Especialista em Direito e Gestão Judiciária pela Academia Judicial do Poder Judiciário do Estado de Santa Catarina. Bacharel em Direito pela Universidade Regional de Blumenau (FURB). E-mail: fas22169@tjsc.jus.br

2 Doutor e Mestre em Direito pela Universidade Federal de Santa Catarina; Professor de Processo Civil do Curso de Graduação em Direito da UFSC; Professor do Curso de Mestrado e Doutorado em Direito da Universidade do Vale do Itajaí-SC e Juiz de Direito Substituto de $2^{\circ}$ Grau do Tribunal de Justiça do Estado de Santa Catarina lotado na 2a Câmara de Direito Público. Email: franciscojneto@uol.com.br

${ }^{3}$ Doutor em Filosofia pela Universidade Federal do Rio Grande do Sul (2009), Mestre em Ciência Jurídica pela Universidade do Vale do Itajaí (2003) e Mestre em Educação pela Universidade Federal de Santa Maria (1999). Professor dos cursos de Mestrado e Doutorado no Programa de Pós-Graduação Stricto Sensu em Ciência Jurídica, do Mestrado em Turismo e da graduação em Direito pela Universidade do Vale do Itajaí UNIVALI. Coordenador do Grupo de Pesquisa e Extensão Paidéia do CNPQ. E-mail: jsoares@univali.br 
SIEGEL, Frederico Adrade; NETO, Francisco José Rodrigues de Oliveira; SOARES, Josemar Sidinei. A guarda, a guarda compartilhada e o poder familiar: implicações práticas. Revista Eletrônica Direito e Política, Programa de Pós-Graduação Stricto Sensu em Ciência Jurídica da UNIVALI, Itajaí, v.11, n.3, 30 quadrimestre de 2016. Disponível em: www.univali.br/direitoepolitica - ISSN 19807791

\section{ABSTRACT}

The " shared custody ", under Brazilian law, has given rise to doubt and confusion among parents or guardians for custody of children, who do not understand the exact duties inherent in parental authority, and believe that sharing just about the time that the less will remain in the company of each. That is why it is necessary to evaluate the regulatory response and the definition of legal categories involving the creation and education of children from family breakdown. For this we used the inductive method.

Keywords: Famil.; Parental authority. Custody. Shared custody.

\section{INTRODUÇÃO}

A presente pesquisa (realizada pelo método indutivo) tem por objetivo apresentar alguns aspectos práticos relacionados ao poder familiar, a guarda e a guarda compartilhada.

A guarda compartilhada foi introduzida em nosso ordenamento jurídico pela Lei no $11.698 / 08$, e posteriormente modificada pela recente Lei $13.058 / 14$, em vigor desde a data da sua publicação, ocorrida em 22 de dezembro de 2014.

Embora a Lei no 13.058/14 tenha vindo ao mundo jurídico para estabelecer o significado da expressão "guarda compartilhada" (art. $1^{\circ}$ ), ainda há certas dúvidas sobre a utilidade prática desse instituto.

A exposição da mídia a respeito da alteração legislativa sobre guarda compartilhada atraiu os pais (ou responsáveis) que estão envolvidos em disputas familiares em relação aos menores para aderirem a esse novo instituto, sem terem a real dimensão do seu alcance prático; vale dizer, por acreditarem que a guarda compartilha significa, pura e simplesmente, a divisão equilibrada do tempo com menor.

Nas audiências de mediação e conciliação envolvendo processos cujos pais (ou responsáveis) disputam a guarda do(a) menor(a), é possível perceber algumas dificuldades práticas quanto ao exercício da guarda, em cotejo com a legislação em vigor (poder familiar). 
SIEGEL, Frederico Adrade; NETO, Francisco José Rodrigues de Oliveira; SOARES, Josemar Sidinei. A guarda, a guarda compartilhada e o poder familiar: implicações práticas. Revista Eletrônica Direito e Política, Programa de Pós-Graduação Stricto Sensu em Ciência Jurídica da UNIVALI, Itajaí, v.11, n.3, 30 quadrimestre de 2016. Disponível em: www.univali.br/direitoepolitica - ISSN 19807791

As implicações práticas da guarda unilateral e da guarda compartilhada têm suscitado questões relevantes na criação dos filhos, inclusive sobre a decisão a respeito do colégio que o menor deve ser inserido, as quais (questões) devem ser resolvidas em consenso pelos pais, independente de uma ou de outra modalidade, em razão do exercício do poder familiar, que não é suspenso (nem parcialmente) com a separação/divórcio do casal.

Em razão disso, mostra-se necessário esclarecer as definições jurídicas a respeito dos institutos do poder familiar, da guarda e da guarda compartilhada, bem como suas implicações práticas.

\section{A DEFINIÇÃo DE FAMÍLIA E A TERMINOLOGIA PARA IDENTIFICAR SEUS MEMBROS}

A definição de família é ponto controverso no meio jurídico e, principalmente, social, em razão do pensamento conservador que defende a validade do casamento (e as consequências jurídicas inerentes a essa instituição) apenas quando constituído por um homem e uma mulher.

Aliás, tramita no Congresso Nacional projeto de Lei 6.583/2013 que define a entidade familiar "como o núcleo social formado a partir da união entre um homem e uma mulher, por meio de casamentou ou união estável, ou ainda por comunidade formada por qualquer dos pais e seus descendentes" ${ }^{4}$.

A visão estreita e discriminatória do Código Civil de 1916, conforme lembrado por Maria Berenice Dias, limitava a família ao grupo originário do casamento ${ }^{5}$. A família e o casamento, portanto, se confundiam.

Atualmente, no entanto, o casamento não se confunde mais com a definição de família. Esta pode ter sua base no casamento ou na união estável, que por sua vez pode ser construída por pessoas do mesmo gênero, ou não.

\footnotetext{
${ }^{4}$ Disponível em www.camara.gov.br acessado em 16/04/2015

${ }^{5}$ DIAS, Maria Berenice. Manual de direito das famílias. 5. ed. rev., atual. e ampl. São Paulo: Editora Revista dos Tribunais, 2009, p. 30
} 
SIEGEL, Frederico Adrade; NETO, Francisco José Rodrigues de Oliveira; SOARES, Josemar Sidinei. A guarda, a guarda compartilhada e o poder familiar: implicações práticas. Revista Eletrônica Direito e Política, Programa de Pós-Graduação Stricto Sensu em Ciência Jurídica da UNIVALI, Itajaí, v.11, n.3, $3^{\circ}$ quadrimestre de 2016. Disponível em: www.univali.br/direitoepolitica - ISSN 19807791

A visão pluralista de família deve abranger os mais diversos arranjos familiares, para que o conceito de família se identifique com o elo de afetividade entre seus membros, independente do gênero das pessoas que a constituem ${ }^{6}$.

Assim, não é o gênero (masculino e feminino), mas sim, o afeto, carinho e amor entre duas ou mais pessoas que constituem a relação familiar.

Sem pretender ingressar nas garantias jurídicas conferidas à união de duas pessoas do mesmo gênero, para fins deste artigo, a família é identificada "pela comunhão de vida, de amor e de afeto no plano da igualdade, da liberdade, da solidariedade e da responsabilidade recíproca"7.

No entanto, nem sempre afetividade é característica perceptível num determinado grupo de pessoas que se acredita formarem uma família. $\mathrm{Na}$ definição de Semy Glanz "a família seria um conjunto de pessoas unidas por uma experiência vivida, ou por uma afeição comum. Mas ela sobrevive sem a 'vivência' e não tem o monopólio da afeição" ${ }^{8}$.

A evolução cultural, que influenciou o aprimoramento jurídico revogou a noção que se tinha a respeito do chefe de família, centrada na figura masculina, na medida em que se estabeleceu igualdade de direitos, independente da natureza do ser humano (art. $5^{\circ}$ da Constituição Federal).

Na modernidade (ou na pós-modernidade) é possível identificar os mais diversos arranjos familiares, como a família constituída apenas por irmã(o)s; avós e neto(a)s; tio(a)s e sobrinho(a)s; família poligâmica dentre tantas outras configurações possíveis que podem ser enquadradas nas duas definições de família, citadas anteriormente.

A abordagem da definição de família se justificada na necessidade de utilizar uma expressão terminológica para identificar os membros da unidade familiar responsáveis pelas decisões a respeito do caminho que ela (a família) deverá

\footnotetext{
${ }^{6}$ DIAS, Maria Berenice. Manual de direito das famílias, p. 30

7 DIAS, Maria Berenice. Manual de direito das famílias, p. 55

8 GLANZ, Semy. A família mutante - sociologia e direito comparado: inclusive o novo Código Civil. Rio de Janeiro: Renovar, 2005, p. 24
} 
SIEGEL, Frederico Adrade; NETO, Francisco José Rodrigues de Oliveira; SOARES, Josemar Sidinei. A guarda, a guarda compartilhada e o poder familiar: implicações práticas. Revista Eletrônica Direito e Política, Programa de Pós-Graduação Stricto Sensu em Ciência Jurídica da UNIVALI, Itajaí, v.11, n.3, $3^{\circ}$ quadrimestre de 2016. Disponível em: www.univali.br/direitoepolitica - ISSN 19807791

seguir, inclusive no que se refere à gerência sobre a vida de seus dependentes (especialmente os menores), afetando, portanto, o exercício da guarda.

É comum utilizar a expressão "pais" para identificar os integrantes da família que decidem seu rumo, sem preponderância do gênero masculino ou da ascendência parental, e que, na ausência de outra expressão corrente, também serve para designar tanto homens ou mulheres que se uniram para formar uma família homoafetiva.

As expressões "pais", "gerentes familiares" ou ainda, "autoridade parental", são utilizadas neste artigo para identificar os seres humanos que, independente da sua natureza, tomam decisões que afetam a entidade familiar e a vida de seus membros, vale dizer, gerenciam a família e a vida de seus integrantes.

\section{ANTECEDENTE HISTÓRICO DO PODER FAMILIAR}

A expressão "poder familiar" sucedeu, com o atual código civil (2002), a expressão "pátrio poder", que remetia à ideia de que a família era governada pelo pai/marido, que se mantinha numa aparente posição de senhor, com amplos direitos para tudo decidir e impor ${ }^{9}$.

Esse poder-dever que era atribuído ao pai, como chefe da família (pater famílias), decorria de uma legitimidade moral em razão dele ser o provedor da necessidade vital (alimento, moradia) dos demais membros da família ${ }^{10}$.

Com conquistas de direitos que antes eram atribuídos apenas ao homem, com reflexo na vida política (voto às mulheres) e na vida econômica (pagamento de salários e oportunidade de emprego, indiferente ao gênero), não havia mais espaço para esse tipo de discurso. Logo, as mulheres adquiriram a merecida e igualitária posição de gerente familiar.

A alteração da expressão respeita a ordem democrática da governança familiar, promovendo a igualdade do poder-dever entre os membros familiares, sejam

9 RIZZARDO, Arnaldo. Direito de Família: Lei 10.406, de 10.01.2002. 7. ed. Rio de Janeiro: Forense, 2009, p. 613

10 FREITAS, Douglas Phillips. Guarda compartilhada e as regras da perícia social, psicológica e interdisciplinar: comentários à lei 11.698 , de 13 de junho de 2008 . Florianópolis: Conceito editorial, 2009, p. 22 
SIEGEL, Frederico Adrade; NETO, Francisco José Rodrigues de Oliveira; SOARES, Josemar Sidinei. A guarda, a guarda compartilhada e o poder familiar: implicações práticas. Revista Eletrônica Direito e Política, Programa de Pós-Graduação Stricto Sensu em Ciência Jurídica da UNIVALI, Itajaí, v.11, n.3, $3^{\circ}$ quadrimestre de 2016. Disponível em: www.univali.br/direitoepolitica - ISSN 19807791

eles do mesmo gênero (união homoafetiva) ou não (heterossexual), cuja divergência entre eles é resolvida pelo juiz.

Atualmente, portanto, preponderam direitos e deveres numa proporção justa e equânime no convívio familiar ${ }^{11}$, respeitando e preservando a igualdade dos valores trazidos pelos "cabeças" da família para dentro do núcleo familiar.

E é com base nesses seus valores que mulheres e homens manifestam seu poder/dever em relação aos caminhos que a família deve seguir, e bem ainda, sobre a vida de seus membros, especialmente dos incapazes.

\section{A DEFINIÇÃO DE PODER FAMILIAR}

A família é a base da sociedade e tem proteção especial do Estado, segundo disposição expressa no art. 226 da Constituição Federal. Essa proteção prevista na constituição inclui todas as famílias, sejam elas oriundas do casamento, da união estável e a família monoparental ${ }^{12}$.

A Constituição Federal também estabelece que é dever dos pais assistir, criar e educar os filhos menores (art. 229, CF). Assim, a ideia de "poder familiar" também tem embutido, em seu conceito, os deveres (obrigações) dos pais (responsáveis) em relação aos menores.

O poder familiar, na definição de Maria Helena Diniz, "é um conjunto de direitos e obrigações, quanto à pessoa e bens do filho menor não emancipado, exercido em igualdade de condições, por ambos os pais, para que possam desempenhar os encargos que a norma jurídica lhes impõe, tendo em vista o interesse e a proteção do filho"13.

Nas palavras de Maria Berenice Dias, o poder familiar "é sempre trazido como exemplo da noção de poder-função ou direito-dever, consagradora da teoria

\footnotetext{
${ }^{11}$ RIZZARDO, Arnaldo. Direito de Família: Lei 10.406, de 10.01.2002, p. 613

12 PETRY JÚNIOR, Henry. A separação com causa culposa: uma leitura à luz da hermenêutica constitucional. Florianópolis: Conceito Editorial, 2007, p. 107

${ }^{13}$ DINIZ, Maria Helena. Curso de direito civil brasileiro. 24. ed. São Paulo: Saraiva, 2009. 5 v, p. 552
} 
SIEGEL, Frederico Adrade; NETO, Francisco José Rodrigues de Oliveira; SOARES, Josemar Sidinei. A guarda, a guarda compartilhada e o poder familiar: implicações práticas. Revista Eletrônica Direito e Política, Programa de Pós-Graduação Stricto Sensu em Ciência Jurídica da UNIVALI, Itajaí, v.11, n.3, 30 quadrimestre de 2016. Disponível em: www.univali.br/direitoepolitica - ISSN 19807791

funcionalista das normas de direito das famílias: poder que é exercido pelos genitores, mas que serve ao interesse do filho"14.

O Código Civil, em seu artigo 1.634, estabelece no que consiste o exercício do poder familiar, mediante as seguintes atribuições conferidas aos pais, quanto à pessoa dos filhos menores:

(i) dirigir-lhes a criação e educação; (ii) tê-los em sua companhia e guarda; (iii) conceder-lhes ou negar-lhes consentimento para casarem; (iv) nomear-lhes tutor por testamento ou documento autêntico, se o outro dos pais não Ihes sobrevier, ou o sobrevivo não puder exercer o poder familiar; (v) representa-los, até os 16 anos, nos atos da vida civil, e assisti-los, após essa idade, nos atos em que forem partes, suprindo-Ihes o consentimento; (vi) reclama-los de quem ilegalmente os detenha; (vii) exigir que lhes prestem obediência, respeito e os serviços próprios de sua idade e condição.

É obrigação dos pais, portanto, garantir o sustento, dirigir a educação e criação dos filhos para proporcionar-lhes a sobrevivência, tonando os filhos úteis à sociedade, enfim, responsabilizando-se pela formação da criança ${ }^{15}$.

E por sustento, compreende-se a obrigação dos pais em prestar aos filhos alimentação, roupas e assistência médica necessária ${ }^{16}$.

Assim como parece óbvio o dever dos pais sustentar os filhos, mas que precisou ser previsto em lei, com a mesma obviedade (embora não mencionada na legislação) surge o dever dos pais em dar amor, afeto e carinho, já que a obrigação constitucional dos pais para com os filhos não se sustenta apenas ao caráter material ${ }^{17}$.

Assim como tornar os filhos uteis à sociedade, na expressão acima mencionada, deve ser compreendido que os pais possuem a responsabilidade em proporcionar os valores éticos e morais, em formatura dos filhos como cidadãos de respeito para com o próximo, à sociedade e o estado.

\footnotetext{
${ }^{14}$ DIAS, Maria Berenice. Manual de direito das famílias, p. 384

${ }^{15}$ VENOSA, Silvio de Salvo. Direito civil: direito de família. 8. ed. São Paulo: Atlas, 2008, p. 302

${ }^{16}$ PETRY JÚNIOR, Henry. A separação com causa culposa: uma leitura à luz da hermenêutica constitucional, p. 66

${ }^{17}$ DIAS, Maria Berenice. Manual de direito das famílias, p. 388
} 
SIEGEL, Frederico Adrade; NETO, Francisco José Rodrigues de Oliveira; SOARES, Josemar Sidinei. A guarda, a guarda compartilhada e o poder familiar: implicações práticas. Revista Eletrônica Direito e Política, Programa de Pós-Graduação Stricto Sensu em Ciência Jurídica da UNIVALI, Itajaí, v.11, n.3, $3^{\circ}$ quadrimestre de 2016. Disponível em: www.univali.br/direitoepolitica - ISSN 19807791

A esse respeito, Arnaldo Rizzardo refere que "a ordem social e o desenvolvimento sadio de um povo dependem em muito do perfeito encaminhamento daqueles que, por não terem atingido a maturidade do corpo e do espírito, necessitam da assistência e da tutela de seus responsáveis" ${ }^{18}$.

É possível perceber, então, que por mandamento legal, o exercício do poder familiar já pressupõe da guarda.

No entanto, essa premissa não é de todo absoluta, pois o poder familiar pode continuar sendo exercido sem que a guarda seja concedida a um dos genitores. Além disso, a guarda pode ser exercida por quem não detém o poder familiar.

É o caso quando decretada a separação/divórcio dos pais; ambos permanecem com o poder familiar, mas apenas um deles exercerá a guarda sobre o menor (na hipótese de não ser adotada a guarda compartilhada). Isso porque, o poder familiar decorre da relação de parentesco, e não da relação havida entre os pais (casamento ou união estável).

Nesse caso, portanto, a separação/divórcio (de fato ou jurídica) não implica perda ou destituição do poder familiar. Ainda que divorciados, os pais preservarão o poder familiar, mas apenas um deles exercerá a guarda.

Outrossim, quando os pais forem suspensos/destituídos do poder familiar, nas hipóteses previstas no art. 1.635 do Código Civil, e o menor for abrigado, ou por qualquer razão, for inserido em família substituta ${ }^{19}$ (art. 28 do ECA), o guardião não terá o poder familiar, mas tão-somente a guarda.

Logo, é possível concluir que o poder familiar pode ser preservado por um dos pais, sem que isso implique no exercício da guarda; e de modo inverso, a guarda poderá ser exercida sem que tenha se originado do poder familiar.

Neste estudo, não se pretende tratar das hipóteses de guarda concedida a terceiro, nas hipóteses de suspensão/destituição do poder familiar (art. 1.634 do Código Civil), mas sim, na guarda resultante da separação/divórcio do casal.

\footnotetext{
18 RIZZARDO, Arnaldo. Direito de Família: Lei 10.406, de 10.01.2002, p. 616.

19 Art. 28. A colocação em família substituta far-se-á mediante guarda, tutela ou adoção, independentemente da situação jurídica da criança ou adolescente, nos termos desta lei.
} 
SIEGEL, Frederico Adrade; NETO, Francisco José Rodrigues de Oliveira; SOARES, Josemar Sidinei. A guarda, a guarda compartilhada e o poder familiar: implicações práticas. Revista Eletrônica Direito e Política, Programa de Pós-Graduação Stricto Sensu em Ciência Jurídica da UNIVALI, Itajaí, v.11, n.3, $3^{\circ}$ quadrimestre de 2016. Disponível em: www.univali.br/direitoepolitica - ISSN 19807791

\section{A DEFINIÇÃO DE GUARDA}

A guarda, prevista no art. 1.583 do Código Civil, admite duas modalidades: guarda unilateral ou compartilhada.

A guarda, assim como o poder familiar, não foi definida pela legislação em vigor. No entanto, o artigo 33 do Estatuto da Criança e do Adolescente estabelece que a guarda "obriga à prestação de assistência material, moral e educacional à criança ou adolescente, conferindo ao seu detentor o direito de opor-se a terceiros, inclusive aos pais".

A guarda é um instituto jurídico cujo exercício por um dos pais não implica perda ou suspensão do poder familiar do outro que não a exerce, no caso da guarda unilateral.

Há uma variedade de situações em que os menores convivem, por longo período de tempo, e por diversas razões, com famílias não biológicas. E para regularizar e fiscalizar essas situações, a lei disciplinou a guarda dos menores, no art. 33, § $1^{\circ}$, do Estatuto da Criança e do Adolescente ${ }^{20}$.

A guarda prevista no Estatuto da Criança e do Adolescente é disciplinada em três modalidades: (i) guarda provisória, concedida liminar ou incidentalmente em processos de adoção (exceto adoção por estrangeiro); (ii) guarda permanente, que atende situações nas quais não se logrou adoção ou tutela, por qualquer motivo; e (iii) guarda peculiar, que atende situações excepcionais ou eventuais, e permite outorga judicial de representação ao guardião para prática de determinados atos em favor do menor ${ }^{21}$.

Além da sua importante utilidade para regularizar situações envolvendo famílias não biológicas, a guarda é indispensável para definir a referência do menor quando seus pais resolvem dissolver o relacionado havido entre eles. E nesse caso, a natureza da guarda é permanente, embora tal situação sempre poderá ser alterada de forma voluntária (entre os pais) ou judicial.

\footnotetext{
${ }^{20}$ VENOSA, Silvio de Salvo. Direito civil: direito de família, p. 272

${ }^{21}$ VENOSA, Silvio de Salvo. Direito civil: direito de família, p. 273
} 
SIEGEL, Frederico Adrade; NETO, Francisco José Rodrigues de Oliveira; SOARES, Josemar Sidinei. A guarda, a guarda compartilhada e o poder familiar: implicações práticas. Revista Eletrônica Direito e Política, Programa de Pós-Graduação Stricto Sensu em Ciência Jurídica da UNIVALI, Itajaí, v.11, n.3, $3^{\circ}$ quadrimestre de 2016. Disponível em: www.univali.br/direitoepolitica - ISSN 19807791

A guarda implica reconhecimento de autoridade e poder de controle na pessoa e na conduta do menor. Também assegura "o direito de estabelecer seu domicílio legal, de permitir que permaneça com terceira pessoa, de orientar e impor o comportamento, de restringir as relações sociais, de obrigar a formação escolar e profissional" 22 .

Considerando que o exercício da guarda por um dos pais não retira o poder familiar do outro, é necessário estabelecer quais as implicações práticas da guarda, na ruptura do relacionamento dos pais.

Como dito, a separação/divórcio não retira ou diminui o poder familiar dos pais. Ainda nesse caso, é necessário do consentimento dos pais (e não apenas do guardião) para conceder ou negar consentimento para casamento (inciso III do art. 1.634 do Código Civil).

Ademais, o pai que não estará exercendo a guarda (unilateral) continuará cumprindo as obrigações previstas nos incisos I, II (a guarda, mencionada nesse inciso, compreendida como direito de visitas) e VII, do art. 1.634 do Código Civil.

A distinção da guarda do poder familiar está na atribuição do guardião, quanto ao inciso V do art. 1.634 do Código Civil.

É certo que o rol previsto no art. 1.634 do Código Civil é apenas exemplificativo, já que não comporta ser esmiuçado para prever todas as situações, diante da complexidade da vida e das relações humanas.

Diante disso, é possível concluir que mesmo com a guarda unilateral, ambos os pais permanecem exercendo o poder familiar sobre o menor, inclusive sobre governança da vida dele, inclusive no que se refere a sua educação (escolha do colégio).

Isso porque, a decisão sobre a escolha do colégio (público ou particular) afeta a situação econômica de quem é obrigado a pagar a pensão alimentícia ao guardião unilateral, de modo que seu interesse não diz respeito apenas à qualidade da educação do filho, mas também sobre a possibilidade financeira de custear esse estudo.

\footnotetext{
${ }^{22}$ RIZZARDO, Arnaldo. Direito de Família: Lei 10.406, de 10.01.2002, p. 577
} 
SIEGEL, Frederico Adrade; NETO, Francisco José Rodrigues de Oliveira; SOARES, Josemar Sidinei. A guarda, a guarda compartilhada e o poder familiar: implicações práticas. Revista Eletrônica Direito e Política, Programa de Pós-Graduação Stricto Sensu em Ciência Jurídica da UNIVALI, Itajaí, v.11, n.3, $3^{\circ}$ quadrimestre de 2016. Disponível em: www.univali.br/direitoepolitica - ISSN 19807791

E todas as decisões sobre a vida do menor que impliquem despesas será de interesse do pai que não detém a guarda unilateral, pode identidade de razão.

\section{A GUARDA COMPARTILHADA E SEUS ASPECTOS PRÁtICOS E JURÍDICOS}

A Lei no $11.698 / 2008$ que previu o instituto da guarda compartilhada está em vigor desde agosto de 2008 (60 dias após a publicação, ocorrida em 13.06.2008), e através dela foi introduzido o $§ 2^{\circ}$ ao art. 1.538 do Código Civil, ao especificar que a guarda unilateral está relacionada com o afeto, saúde, segurança e educação.

A Lei no 13.058, em vigor desde a data da sua publicação, ocorrida em 22.12.2004, revogou os incisos I, II e III do $\S 2^{\circ}$ do art. 1.538 do Código Civil, e embora tenha mencionado, em seu art. $1^{0}$ que "esta Lei estabelece o significado da expressão 'guarda compartilhada'", apenas alterou a redação do § 20 do art. 1.583 para o seguinte teor: "Na guarda compartilhada, o tempo de convívio com os filhos deve ser dividido de forma equilibrada com a mãe e com o pai, sempre tendo em vista as condições fáticas e os interesses dos filhos".

A referida lei também alterou a redação do $\S 3^{\circ}$ do referido artigo: "Na guarda compartilhada, a cidade considerada base de moradia dos filhos será aquela que melhor atender aos interesses dos filhos".

A legislação em comento não estabeleceu qualquer outra definição ou significado além destes acima mencionados. Ainda, alterou a redação do art. 1.634 para frisar que o poder familiar será exercido por ambos os pais "qualquer que seja sua situação conjugal".

Logo, a referida legislação apenas ratificou entendimento segundo o qual a guarda não esvazia o poder familiar de nenhum dos pais, inclusive daquele em relação ao qual a guarda não é exercida.

A única implicação em deferir a guarda a um dos pais, no momento da separação/divórcio, é a referência que o menor terá a respeito de onde será o seu lar, e quem terá a responsabilidade de visitá-lo. 
SIEGEL, Frederico Adrade; NETO, Francisco José Rodrigues de Oliveira; SOARES, Josemar Sidinei. A guarda, a guarda compartilhada e o poder familiar: implicações práticas. Revista Eletrônica Direito e Política, Programa de Pós-Graduação Stricto Sensu em Ciência Jurídica da UNIVALI, Itajaí, v.11, n.3, $3^{\circ}$ quadrimestre de 2016. Disponível em: www.univali.br/direitoepolitica - ISSN 19807791

A guarda e o poder familiar são institutos cujo exercício, relacionados aos pais separados ou divorciados, se confundem, e apenas se diferenciam para estabelecer o domicílio legal do menor e assistir ou representá-lo, que passam a ser atribuições exclusivas do guardião.

$\mathrm{Na}$ guarda compartilhada, conforme referido por Douglas Philips Freitas, "os genitores passam a tomar decisões sobre os filhos de forma conjunta e consensual, ambos fazendo parte do dia-a-dia da criança ou do adolescente, inexistindo a figura do cônjuge visitante" ${ }^{23}$.

No entanto, essas decisões adotadas de forma conjunta e consensual não são exclusividade da guarda compartilhada.

A lei que introduziu a guarda compartilhada no ordenamento jurídico não estabeleceu que as decisões sobre a vida do menor devem ser adotadas em conjunto ou de forma consensual.

A referida legislação não disciplinou que na guarda unilateral apenas o guardião adota determinadas decisões, enquanto na guarda compartilhada as decisões sobre a vida do menor deve ser exercida de forma conjunta e consensual.

A recente Lei no 13.058/14 apenas disciplinou que o tempo de convívio com os filhos deve ser dividido de forma equilibrada entre os pais, quando a guarda compartilhada for adotada.

Ainda, o poder de supervisão previsto na nova redação do $\S 5^{\circ}$ do art. 1.583 do Código Civil não retira o poder-dever decisório que os pais exercem sobre os menores, decorrentes do poder familiar, ainda que adotada a guarda unilateral.

A ausência de definição jurídica a respeito da guarda unilateral, ou sua sobreposição ao poder familiar, implica concluir que os limites da primeira (guarda unilateral) não são superiores a este último (poder familiar).

\footnotetext{
${ }^{23}$ FREITAS, Douglas Philips. Guarda compartilhada e as regras da perícia social, psicológica
} e interdisciplinar: comentários à lei 11.698, de 13 de junho de 2008, p. 41 
SIEGEL, Frederico Adrade; NETO, Francisco José Rodrigues de Oliveira; SOARES, Josemar Sidinei. A guarda, a guarda compartilhada e o poder familiar: implicações práticas. Revista Eletrônica Direito e Política, Programa de Pós-Graduação Stricto Sensu em Ciência Jurídica da UNIVALI, Itajaí, v.11, n.3, 30 quadrimestre de 2016. Disponível em: www.univali.br/direitoepolitica - ISSN 19807791

\section{CONSIDERAÇÕES FINAIS}

Antes da guarda compartilhada ser introduzida pela Lei 11.698 em 2008 (modificada em 2014 pela Lei 13.058) era comum, e ainda é, definir a guarda a favor de um dos pais, com direito de visita livres ao outro, nos processos envolvendo a ruptura familiar.

E em razão da estipulação livre do direito de visitação, o tempo de convívio com os filhos era (ou ainda é) divido de forma equilibrada entre os pais, dependendo da situação peculiar de cada ex-casal.

A guarda compartilhada não trouxe implicações práticas sobre a governança da vida do menor, para diferenciá-la da guarda unilateral, pois a guarda não tem o condão de suspender o exerć́cio parcial do poder familiar em relação àquele pai (ou mãe) que não detém a guarda.

A legislação não especificou se há algum poder (ou dever), no exercício da guarda unilateral, superior ao poder familiar em relação ao pai (ou mãe) que não detém a guarda.

Assim, decisões sobre a governança da vida do menor, inclusive sobre o colégio no qual ele será inserido, devem ser tomadas em consenso pelos pais, independente de ter sido estipulada a guarda compartilhada, por força do disposto no art. 1.634, I, do Código Civil.

Por fim, vale ressaltar que a distinção entre guarda compartilhada, e guarda unilateral com direito de visitação livre, pode ser percebida, quanto à primeira, no tempo de convívio equilibrado dos pais com o menor decorre de uma obrigação judicial; enquanto na segunda (guarda unilateral), esse tempo de convívio equilibrado é estabelecido de forma voluntária e consensual pelos pais.

\section{REFERÊNCIAS BIBLIOGRÁFICAS}

DIAS, MARIA BERENICE. Manual de direito das famílias. 5. ed. rev., atual. e ampl. São Paulo: Editora Revista dos Tribunais, 2009.

DINIZ, Maria Helena. Curso de direito civil brasileiro. 24. ed. São Paulo: Saraiva, 2009. 5 v. 
SIEGEL, Frederico Adrade; NETO, Francisco José Rodrigues de Oliveira; SOARES, Josemar Sidinei. A guarda, a guarda compartilhada e o poder familiar: implicações práticas. Revista Eletrônica Direito e Política, Programa de Pós-Graduação Stricto Sensu em Ciência Jurídica da UNIVALI, Itajaí, v.11, n.3, 30 quadrimestre de 2016. Disponível em: www.univali.br/direitoepolitica - ISSN 19807791

FREITAS, Douglas Phillips. Guarda compartilhada e as regras da perícia social, psicológica e interdisciplinar: comentários à lei 11.698 , de 13 de junho de 2008. Florianópolis: Conceito editorial, 2009.

GLANZ, Semy. A família mutante - sociologia e direito comparado: inclusive o novo Código Civil. Rio de Janeiro: Renovar, 2005.

PETRY JÚNIOR, Henry. A separação com causa culposa: uma leitura à luz da hermenêutica constitucional. Florianópolis: Conceito Editorial, 2007.

RIZZARDO, Arnaldo. Direito de Família: Lei 10.406 de 10.01.2002. 7. ed. Rio de Janeiro: Forense, 2009.

VENOSA, Silvio de Salvo. Direito civil: direito de família. 8. ed. São Paulo: Atlas, 2008.

Submetido em: setembro/2016

Aprovado em: novembro/2016 